\title{
Imaging and Tracking of Tat Peptide-Conjugated Quantum Dots in Living Cells: New Insights into Nanoparticle Uptake, Intracellular Transport, and Vesicle Shedding
}

\author{
Gang Ruan ${ }^{\ddagger 1}$, Amit Agrawal $^{\ddagger 1}$, Adam I. Marcus $^{2}$, and Shuming Nie ${ }^{\star 1,3}$ \\ ${ }^{1}$ Department of Biomedical Engineering, Emory University and Georgia Institute of \\ Technology, 101 Woodruff Circle, Suite 2001, Atlanta, GA, 30322 \\ ${ }^{2}$ Winship Cancer Institute, Emory University School of Medicine, Atlanta, GA, 30322 \\ ${ }^{3}$ Department of Chemistry, Emory University, Atlanta, GA, 30322 \\ ${ }^{\ddagger}$ Authors who contributed equally to this work.
}

*Author to whom correspondence should be addressed; e-mail: snie@emory.edu.

\section{Supplementary Materials}

Supplementary Video 1: Directed motion of Tat-QDs from the cell periphery toward a perinuclear region called microtubule organizing center (MTOC) (frames 21 to 29) at 4 frames per second. Faster imaging speeds at 10-20 frames per second showed similar directed transport behavior. One pixel is equivalent to $64 \mathrm{~nm}$ in distance.

Supplementary Video 2: Directed motion of Tat-QDs along cell peripheral tracks and filopodia (frames 5 to 13) recorded at 4 frames per second.

Supplementary Video 3: Motion of Tat-QDs within the perinuclear MTOC region recorded at 4 frames per second.

Supplementary Video 4: Motion of Tat-QDs in cytoplasmic organelles (vesicles) recorded at 3 frames per second.

Supplementary Video 5: Motion of Tat-QDs trapped in vesicles along filopodia recorded at 15 frames per second. 